\title{
GRAMÁTICA E TEXTO: O TRABALHO COM AS PREPOSIÇÕES
}

Tatiane Henrique Sousa Machado ${ }^{1}$

MACHADO, T. H. S. Gramática e texto: o trabalho com as preposições. EDUCERE - Revista da Educação, Umuarama, v. 17, n. 2, p. 273-290, jul./dez. 2017

RESUMO: No presente estudo analisou-se uma proposta de ensino das preposições presente no livro didático "Português: leitura, produção, gramática", de Leila Lauar Sarmento da $6^{\text {a }}$ série do Ensino Fundamental. Para tanto, partiu-se do escopo funcionalista de análise da língua, objetivando aliar as contribuições teóricas desse escopo à prática de ensino. Observou-se que o livro didático analisado apresenta diferentes gêneros textuais dos quais presume partir a análise linguística, contudo, esses textos não são explorados, servindo apenas de pretexto. Destacou-se a preocupação com a explicitação dos sentidos oriundos das preposições, no entanto, os sentidos mencionados foram restritos, revelando uma concepção de gramática desvinculada da interação verbal.

PALAVRAS-CHAVE: Abordagem Funcionalista; Ensino de Gramática; Preposição.

\section{GRAMMAR AND TEXT: WORKING WITH PREPOSITIONS}

ABSTRACT: This study analyzed a proposal for teaching prepositions as presented in the textbook "Português: leitura, produção, gramática" by Leila Lauar Sarmento for the $6^{\text {th }}$ grade of elementary school. It started from a functionalist scope of the language analysis, aiming to combine the theoretical contributions of that scope to the teaching practice. It was observed that the textbook has analyzed different textual genres from which it starts to develop the linguistic analysis. However, these texts are not exploited, being used only as a pretext. It highlights the concern with

DOI: $10.25110 /$ educere.v17i2.2017.6602

${ }^{1}$ Doutoranda da Universidade Estadual de Maringá no Programa de Pós-Graduação em Letras. Professora da Universidade Paranaense - UNIPAR, Campus Umuarama-Sede. E-mail de contato: tatiane@prof.unipar.br 
the explanation of the senses arising from prepositions; the mentioned senses were restricted, revealing a grammar concept divorced from verbal interaction.

KEYWORDS: Functionalist approach; Preposition; Teaching Grammar.

\section{GRAMÁTICA Y TEXTO: EL TRABAJO CON LAS PREPOSICIONES}

RESUMEN: En el presente estudio se analizó una propuesta de enseñanza de las preposiciones presente en el libro didáctico "Portugués: lectura, producción, gramática", de Leila Lauar Sarmento de la $6^{\text {a }}$ serie de la Enseñanza Fundamental. Para ello, se partió del ámbito funcionalista de análisis de la lengua, objetivando aliar las contribuciones teóricas de ese alcance a la práctica de enseñanza. Se observó que el libro didáctico analizado presenta diferentes géneros textuales de los que presume partir el análisis lingüístico, sin embargo, esos textos no son explotados, sirviendo sólo de pretexto. Se destacó la preocupación por la explicitación de los sentidos oriundos de las preposiciones, sin embargo, los sentidos mencionados fueron restringidos, revelando una concepción de gramática desvinculada de la interacción verbal.

PALABRAS CLAVE: Enfoque funcional; Enseñanza de Gramática; Preposición.

\section{INTRODUÇÃO}

O ensino de gramática tradicionalmente tem ocorrido de modo descontextualizado das regras de uso e com excessivo predomínio da metalinguagem. Contudo, a partir da década de 90 inúmeras pesquisas de diferentes áreas apontaram à necessidade de renovação desse tipo de ensino. Desse modo, contribuições da Análise do Discurso, da Linguística Textual e do Funcionalismo, aliadas aos documentos oficiais destacam a importância de o ensino da língua basear-se no uso, mediante atividades de análise linguística, ou seja, "atividades epilinguísticas e metalinguísticas que estimulam a reflexão sobre a língua” (BRASIL, 1997, p. 38).

Neste contexto, as pesquisas funcionalistas sobre o processo de gramaticalização têm suscitado novas posturas no tratamento da língua e, consequentemente, no ensino desta, pois incitam questionamentos sobre 
como tratar as mudanças linguísticas em sala de aula. Por conseguinte, os Parâmetros Curriculares Nacionais (PCNs) preveem que uma das funções da escola é formar um leitor e escritor competente, capaz de utilizar diferentes recursos da língua conforme os diferentes contextos de uso. Portanto, é consenso de que " a gramática a ser ensinada na escola deve levar o aluno a refletir sobre o uso efetivo da língua, considerando o convívio com as variantes linguísticas, incluindo a norma considerada padrão" (ANTONIO, 2005, p. 2).

A partir dessa problemática, propõe-se neste estudo analisar uma proposta de ensino das preposições apresentada no livro didático "Português: leitura, produção, gramática", de Leila Lauar Sarmento da $6^{\mathrm{a}}$ série do Ensino Fundamental. A escolha desse material deve-se a sua utilização em algumas escolas da rede de ensino fundamental da cidade de Umuarama.

O suporte de análise baseia-se no escopo funcionalista, visando destacar como os estudos funcionalistas podem contribuir para o ensino de língua materna, particularmente, nesta pesquisa das preposições. Para tanto, elegem-se os seguintes objetivos específicos: a) examinar o encaminhamento do ensino das preposições no livro didático; b) expandir a proposta apresentada no livro didático, a partir do escopo adotado neste estudo; c) destacar por meio do conceito de semanticização a contribuição das preposições para atribuição de sentido do enunciado.

Parte-se da seguinte hipótese: as preposições têm sido negligenciadas nos encaminhamentos dos livros didáticos, já que tradicionalmente são tomadas como palavras "vazias de sentido", contudo, os pressupostos funcionalistas evidenciam que as preposições possuem sentidos prototípicos e derivados. Sendo assim, a função das preposições não se limita à mera conexão entre palavras, pois ao ligaram argumentos indicam determinados sentidos possíveis, fundamentais para a compreensão do enunciado.

\section{CONTRIBUIÇÕES DA CORRENTE FUNCIONALISTA}

Tradicionalmente atrela-se gramática à impressão negativa ou mesmo utilitária, vinculada às práticas de aprendizagem ritualísticas de rotulação, reconhecimento de classes e subclassificações. Essa postura 
revela a compreensão da gramática como simples mapa taxonômico de categorias, alheio à língua em funcionamento e independente da interação (NEVES, 2004).

Em contraponto, a teoria funcionalista pode contribuir com uma possível alternativa para o ensino gramatical, por embasar-se na organização gramatical das línguas naturais, aliada à interação social (NEVES, 1997). Nessa perspectiva, o ensino de gramática não é reconhecido como estanque, homogêneo e imutável, mas sim um ensino que objetiva auxiliar o aluno produzir enunciados adequados à situação comunicativa, ou seja, objetivando a competência comunicativa.

A abordagem funcionalista preocupa-se com a estrutura gramatical no interior de uma situação real de comunicação, considerando o objetivo da interação, os participantes e o contexto discursivo (FURTADO DA CUNHA, OLIVEIRA, MARTELOTTA, 2003), já que o propósito comunicativo motiva um determinado comportamento linguístico dando-lhe uma forma.

Um dos conceitos discutidos pelos funcionalistas reside no fato de a gramática ser constantemente renovada. As atividades discursivas variadas promovem usos variados do sistema linguístico, reorganizando-o, denominando-se gramaticalização. Entretanto, os usos mais antigos de uma forma linguística, de onde as novas funções se derivam, não desaparecem necessariamente, bem como o novo uso pode ser discriminado por um tempo, mas aos poucos são aceitos pela comunidade linguística (HINTZE, 2009, p. 86).

Essas mudanças não são aleatórias, pois frequentemente nota-se a vinculação de fatores cognitivos, que por extensão metafórica (traços semânticos) motivam o falante para a criação de "novos" sentidos. Um exemplo é o caso da preposição facies (face, semblante, beleza, ar aparência), para em face de (utilizada para aspectos concretos e abstratos) (CASTILHO, 2010), ou seja, novos usos são promovidos em consonância as diferentes intenções comunicativas.

Esse processo de criação de novos sentidos ativados por dispositivos sociocognitivos dá-se o nome de semanticização, em oposição à dessemantização que é desativação e a ressemantização (recategorizar). A semântica cognitiva oferece inúmeras contribuições para fundamento desses conceitos, pois estabelece relevos dos participantes de uma dada 
cena (figura e fundo), bem como relacionar o discurso aos espaços mentais.

Desse modo, o presente estudo partirá do conceito de semanticização, destacando que erroneamente as preposições têm sido tomadas como "vazias" de sentido. Essa concepção, muitas vezes, pode engendrar um ensino mecânico, como se os sentidos fossem estanques. Assim, na próxima seção apresentam-se alguns conceitos tradicionais e funcionalistas de preposição, já que o ângulo de observação da língua pressupõe tratamentos distintos no ensino que pode ser prescritivo ou crítico.

\section{CONCEITO DE PREPOSIÇÃO}

As preposições são tradicionalmente denominadas palavras invariáveis que precedem uma unidade nominal, exercendo a função de conectivos, ou seja, classe que desempenha a função de ligação. Para Almeida (2005, p. 334, grifo do autor) "a preposição liga palavras (substantivo a substantivo, substantivo a adjetivo, substantivo a verbo, adjetivo a verbo, etc.)". Denominando-a de "palavra invariável que tem por função ligar o complemento à palavra completada (do latim prae=diante de, positionem=posição) pelo fato de porem na frente de uma palavra outra que a completa" (ALMEIDA, 2005, p. 334). Esse mesmo autor assevera que as preposições não têm significação intrínseca, própria, mas sim relativa, pois dependem do verbo com o qual são empregadas.

Semelhantemente, Azeredo (2010, p. 196) entende que "as preposições são palavras invariáveis que precedem uma unidade nominal, convertendo-a em constituinte de uma unidade maior". Todavia, para Azeredo (2010) as preposições contribuem de forma mais ou menos relevante para o significado das construções que participam, já que em alguns casos a preposição não é escolhida, mas sim imposta pelo contexto sintático (dependo de você).

Além das preposições, as gramáticas destacam as locuções prepositivas, ou seja, combinação estável de palavras que equivale a uma preposição (AZEREDO, 2010). As locuções prepositivas (ou preposicional) são geralmente formadas por advérbios ou locuções adverbiais acrescidas da palavra de (ou ainda a ou com) (SAID ALI, 1964).

Etimologicamente segundo Said Ali (2001, p. 154) as preposi- 
ções latinas foram primitivamente advérbios, por isso desempenham papel análogo aos dos sufixos dos antigos casos oblíquos. Aparecem antepostas a substantivos e pronomes acrescentando-lhes a noção de lugar, instrumento, meio, posse, dentre outros (SAID ALI, 2001). Contudo, esse mesmo autor assevera que o uso das preposições, originalmente teve um sentido delimitado que sofreu alterações, em detrimento das associações de ideias, alargando o seu domínio semântico.

Cunha e Cintra (2007, p. 555) conferem sentidos espaciais, temporais ou nocionais as preposições, denominando-as de "palavras invariáveis que relacionam dois termos de uma oração, de tal modo que o sentido do primeiro (antecedente) é explicado ou completado pelo segundo (consequente)". Para esses autores a significação das preposições reside na relação que implica movimento ou não-movimento (situação resultante) aplicável aos campos espacial, temporal e nocional.

No mesmo contexto, adotando uma abordagem funcionalista Poggio (2002), propõe que as preposições são partículas relacionais que exercem um papel importante na comunicação, pois são elementos fundamentais na estrutura linguística. Essa autora acrescenta que as preposições estruturam metáforas ligadas à orientação espacial; logo, não arbitrárias em virtude de se basearem nas experiências físicas do homem (em cima, embaixo, fora, atrás). Para tanto, essa autora retoma Lakoff (1980), que entende o tempo como uma metáfora de um objeto em movimento. Portanto, no ponto de vista do homem o tempo vem depois dele "de frente para trás".

Sob o mesmo escopo da autora anterior Castilho (2010), compreende que,

as preposições são palavras invariáveis que atuam como: i) ligação de palavras e de sentenças; ii) função semântica: atribuição ao seu escopo de um sentido geral de localização no espaço; iii) função discursiva: acréscimo de informações secundárias ao texto e a organização do texto (CASTILHO, 2010, p. 583).

Ou seja, as preposições, tradicionalmente, entendidas como "vazias de sentido", na verdade possuem um sentido de base, o de localização espacial ou temporal, fato esse, nem sempre percebido (CASTILHO, 2010). Para esse autor as preposições são reconhecidas quando expressam 
as categorias: posição no espaço, deslocamento no espaço, e distância no espaço. Contudo, os sentidos de base convivem com outros sentidos, não prototípicos, denominados por Castilho (2010) de sentidos derivados, frutos de processos metafóricos.

Desse modo, para Castilho (2010, p. 584), “as preposições são operadores que realizam a relação assimétrica entre o objeto A que queremos localizar (FIGURA) e o objeto B com referência ao qual queremos localizar o objeto A (PONTO DE REFERÊNCIA)." Essa localização é assimétrica em virtude de que a relação entre o objeto e o ambiente em que ele está localizado, leva em consideração conhecimentos reais, tais como: tamanho, conteúdo, orientação, ordem, direção, distância, movimento. Fato esse que segundo Castilho (2004) explica a ínfima incidência de a mesa debaixo do livro.

A partir dessas considerações Castilho $(2004,2010)$ propõe os eixos das preposições, isto é: a) eixo horizontal (localização lateral) indicando a imagem do percurso, de deslocamento pelos traços inicial e origem (desde, a partir de), ponto medial (por, no meio de), ponto final (a, para, atém em, contra); b) eixo vertical- localização superior (sobre, por cima de) e localização inferior (sob, embaixo de); c) eixo transversal - localização anterior (ante, antes de, diante de, em frente de ) e localização posterior (atrás, por trás de, após, depois); d) Eixo da proximidade: localização proximal (perto de, acerca de) e distal (longe de, distante de); e e) eixo continente/conteúdo: dentro (em, com, entre, dentro de) e localização fora (sem, fora de, na ausência de).

Logo, as preposições têm sentidos prototípicos, dados por categorias e subcategorias cognitivas que se desdobram por vários processos semânticos derivados. Os sentidos prototípicos correspondem às categorias semântico-cognitivas de posição no espaço, deslocamento no espaço, distância no espaço e movimento; contudo, não se pode pensar em representação fiel, dada a criatividade humana que promove alterações em consonância as diferentes necessidades de interação (CASTILHO, 2004), uma vez que esses usos são constantemente "renovados".

Diante das considerações discutidas, na próxima seção será analisada uma proposta de ensino das preposições, destacando possíveis lacunas, bem como contribuições do escopo funcionalista para a prática docente. 


\section{O ENSINO DAS PREPOSIÇÕES NOS LIVROS DIDÁTICOS}

A proposta a seguir foi selecionada do livro didático de Língua Portuguesa ( $6^{\mathrm{a}}$ série), da autora Leila Lauar Sarmento e objetiva-se o tratamento didático do conteúdo: preposição.

Conforme o suplemento de orientações para o professor o "objetivo maior do ensino da língua materna é o domínio dos usos da linguagem em várias situações sociais para o desenvolvimento da competência comunicativa" (SARMENTO, p. 5, suplemento). Nessas orientações percebe-se o discurso oficializado nos Parâmetros Curriculares de que o ensino deve partir da reflexão e uso. Assim, a proposta didática, teoricamente, atende às recomendações educacionais institucionalizadas.

O livro organiza-se em unidades temáticas divididas em: 1) contextualização (introdução do conteúdo gramatical por meio de um texto); 2) conceitualização (exposição do conteúdo gramatical) e; 3) aplicação (exercícios de aplicação imediata).

$\mathrm{Na}$ unidade analisada apresenta-se inicialmente um texto "De Apolinário a Poço Fundo"(fig.01), no qual todas as preposições foram grifadas. 
Figura 1: Início da unidade de tratamento da preposição

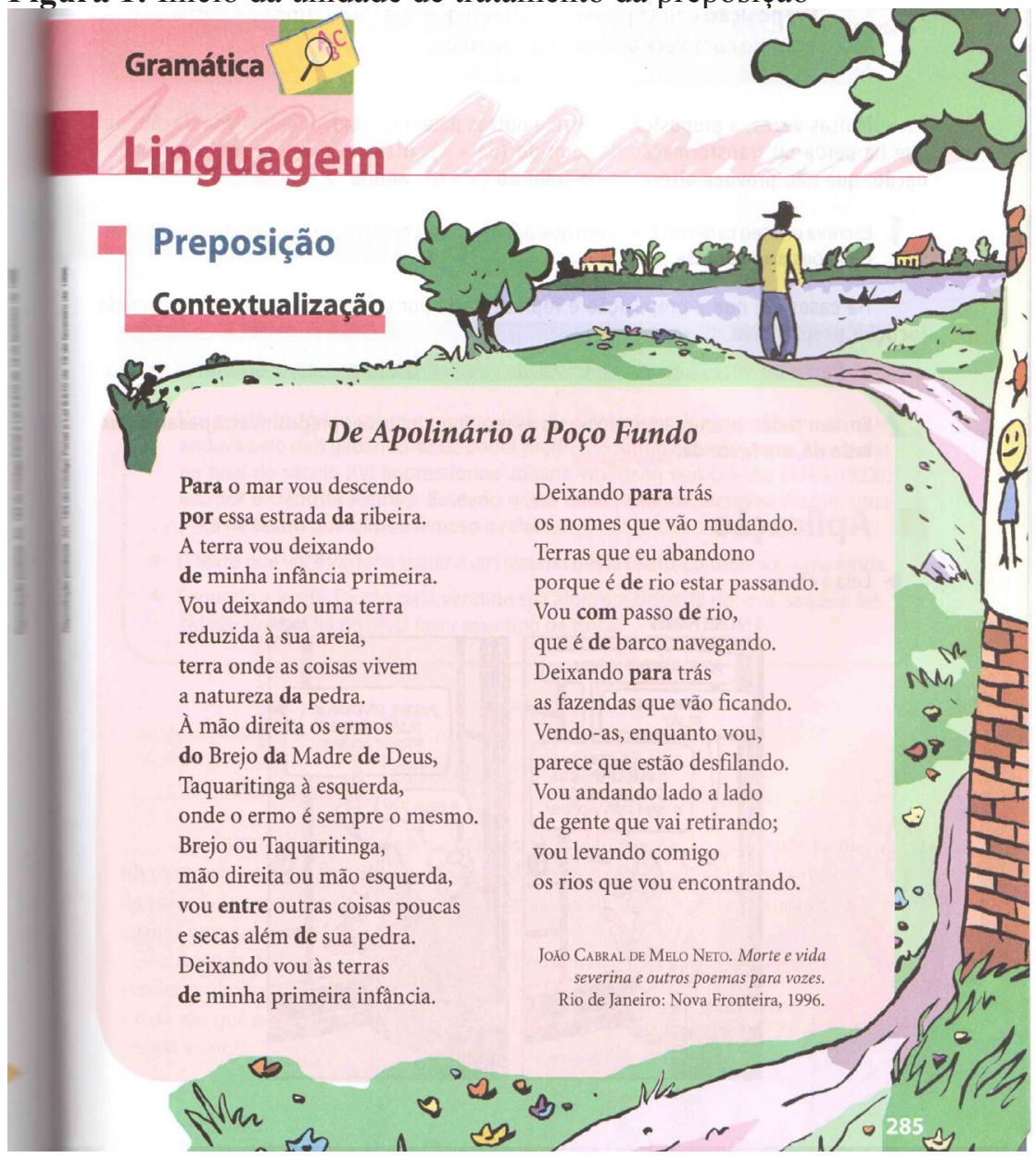

Conforme orientam os Parâmetros Curriculares Nacionais (PCNs) a proposta de ensino de língua materna do livro parte de um texto, entretanto, de cunho literário, um poema de João Cabral de Melo Neto. Ressalta-se que o texto selecionado não se configura como um texto cotidiano, mas sim estilisticamente pensado para a literatura. Assim, ao apresentar primeiramente o texto percebe-se uma tentativa de tratamento da aprendizagem, consoante aos pressupostos teóricos de que o texto 
deve ser o ponto de partida e de chegada no ensino de língua materna; Todavia, esse material é utilizado exclusivamente para destacar as preposições, não sendo explorado em momento algum da unidade qual a função e a distinção dos usos das preposições presentes neste poema, ou seja, configurou-se como mero pretexto, em detrimento da quantidade de preposições presentes. Logo, fica a cargo do docente explorá-lo consoante ao seu objetivo: ensino das preposições.

Na sequência (próxima página) o livro apresenta a seguinte explicação: "As palavras destacadas ligam o segundo termo ao primeiro, ao qual completam. Expressam um sentido dentro do contexto. São palavras invariáveis que se chamam preposições" (SARMENTO, 2006, p. 286, grifo da autora).

Em seguida (fig.2) o conceito tradicional de preposição, em que se faz paráfrase do conteúdo exposto anteriormente. Nota-se a mera "etiquetagem" seguida de explicações morfológicas sobre algumas contrações das preposições. Na sequência, propõe-se que o aluno escreva frases (desvinculadas de uma situação) utilizando algumas preposições selecionadas pelo autor.

Por mais que as orientações previstas no livro didático apresentem que o ensino deve estimular "o domínio dos usos em várias situações”, nota-se que o ensino gramatical ainda está atrelado às fórmulas. Esse tipo de encaminhamento pressupõe que munido do conhecimento gramatical (em porções menores), posteriormente, o aluno transferiria tais conceitos à produção textual. Portanto, entende-se que a produção textual e a leitura podem ser vinculadas ao uso, por meio de diferentes gêneros, mas a gramática não.

Nesse tipo de tratamento, não se observa que todo e qualquer gênero textual dotado de características relativamente estáveis é dotado de um tema, composição e estilo que existem em função de uma determinada finalidade, circulação social, bem como interlocutores, ou seja, no ato da escrita caberá ao escrevente pensar em quais recursos estilísticos contribuirão para o alcance do seu objetivo. 
Figura 2: Conceito de preposição

\section{Conceituação}

Preposição é uma palavra invariável que liga dois termos de forma que o segundo completa o sentido do primeiro.

Muitas vezes, a preposição une-se a outras palavras formando uma contração, em que há perda ou transformação de som: do (de $+o)$, nisso $(e m+$ isso) ou uma combinação, que não provoca alteração de som: ao $(a+0)$, aonde $(a+o n d e)$.

1 Escreva em seu caderno frases em que apareçam as contrações na, pelo, desse e as combinações aos e aonde.

Há casos em que a preposição é representada por um grupo de palavras chamado locução prepositiva. Observe:

- Perto de você, não existe tristeza.

- 0 cão passeava ao lado do dono.

2 Em seu caderno, empregue em frases as seguintes locuções prepositivas: apesar de, ao lado de, em favor de.

A próxima etapa, intitulada "Aplicação" (figuras 3 e 4), pressupõe uma atividade prática de uso das preposições no texto, todavia, novamente limita-se a solicitar que o aluno realize uma atividade mecânica de "cópia" das frases em que aparecem preposições que expressam lugar e falta ou carência.

Observa-se que em nenhum momento foi discutido o sentido prototípico das preposições em relação a lugar, nem mesmo os demais sentidos que foram sendo "criados" pelos diferentes usos, ou seja, a semanticização das preposições.

Destaca-se que não se espera que esses pressupostos sejam explorados em sala de aula como recurso metalinguístico, mas sim que subsidiem as discussões de ensino gramatical de leitura e escrita, objetivando promover a competência comunicativa do aluno. 
Figura 3: Atividades de aplicação dos conhecimentos

\section{Aplicação}

Leia a charge.
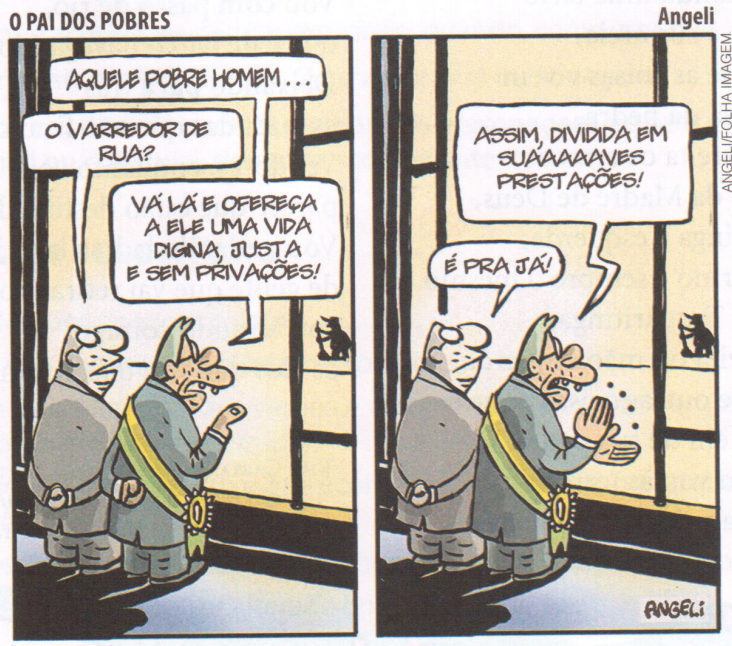

Figura 4: Atividades de aplicação dos conhecimentos

a) A charge permite concluir que o político nela representado vai oferecer ao varredor uma vida justa? Por quê? Năo. Fica evidente que o politico vai apenas iludir o varredor.

b) O que você pensa sobre a desigualdade social? Resposta pessoal.

c) Qual foi o efeito produzido pela utilização, no $2^{\circ}$ quadrinho, do adjetivo suaves com a vogal a repetida? Esse recurso visou mostrar que seriam inúmeras as prestaçōes a serem pagas pelo servidor publico.

d) Copie no caderno as frases em que aparecem, na charge, as preposições que expressam lugar e falta ou carência. Empregue essas preposições em frases, com o mesmo sentido. "O varredor de rua?" (lugar); "[...] ofereça a ele uma vida [...] sem privaçōes." (falta ou carência). Resposta pessoal.

As quatro perguntas apresentadas dedicam-se a observar: i) a percepção do conteúdo implícito do texto; ii) estimular a exposição de respostas pessoais; iii) discutir o uso do adjetivo e da repetição das vogais para garantir a intensidade do vocábulo, conduzindo ironicamente o 
enunciado e; iv) analisar as preposições das expressões: varredor de rua e vida sem restrições, indicadas com o sentido de lugar e falta/carência.

Nessa proposta de aplicação várias informações ficaram a cargo de o docente explorar. Na sequência, apresentam-se algumas discussões pertinentes à luz da teoria funcionalista.

A preposição “de”, conforme Neves (2000), dentre seus diversos sentidos pode classificar um determinado objeto, indicando a inclusão em uma classe, tal como o exemplo apresentado pela autora: "O Ministro DAS Relações Exteriores do Brasil teme (...)” (NEVES, 2000, p. 663, grifos da autora). A preposição "de" neste exemplo não visa atribuir meramente o sentido de espaço (Brasil). Do mesmo modo em varredor de rua (grifo nosso) percebe-se que "de rua" pode sim remeter ao lugar (a ser varrido), mas também distingue esse profissional de outros, especificando-o como no exemplo de Neves.

Neves (2000) acrescenta que em muitos casos, o léxico possui um adjetivo classificador correspondente ao sintagma nominal iniciado por "de", por exemplo, indústrias alimentícias (=de alimento). Fato esse também pertinente à charge, já varredor (sem especificação), também conhecido como gari (regionalismo), proveniente de Aleixo Gary incorporador da empresa de limpeza das ruas no Rio de Janeiro (HOUAISS, 2009), ou seja, uma semanticização por metonímia.

Desse modo, ao apresentar exclusivamente uma ocorrência do uso da preposição "de" o aluno pode generalizar esse uso, fato não verdadeiro no cotidiano, pois em expressões comuns do português brasileiro tem-se: "A moça fez-se de rogada (ART)" (NEVES, 2000, p. 666), em que a preposição indica uma condição. Outro uso freqüente previsto em Houaiss (2009): "Peguei a mala e fui ao Hotel das Flores" (denominação), "linda de morrer" (intensificador), "chegou do Paraná" (procedência),"anel de prata" (matéria), "desmaiou de fome" (causa),"sair de fininho" (modo), "saiu de manhã" (tempo) ou ainda "vestido de festa" (finalidade), ou seja, os sentidos deslocam-se pelo eixo mais concreto (espaço) para o mais abstrato (intensificador, modo, dentre outros possíveis), tal como compreende Castilho (2010).

Portanto, a preposição "de" presente no livro didático classificada como sentido de lugar não confere exclusivamente o sentido de lugar, uma vez que existem inúmeros outros sentidos admitidos, que não foram 
contemplados ou explorados nos encaminhamentos metodológicos.

Diferentemente da preposição "de" confere-se a preposição "sem" uma relação mais estreita de sentido. Segundo Poggio (2002, p. 99), "há preposições estreitamente ligadas a certos casos", dentre elas destaca-se a preposição SEM, estreitamente ligada "ao caso "maneira". Essa conexão, segundo essa mesma autora, vincula seu sentido à ideia de modo, maneira, presente desde a sua origem, contudo, outro significado possível para a preposição sine (expressões latinas, como: conditio sine qua non) vincula seu uso também a ideia de condição. Semelhantemente a preposição "de" observa-se uma abstratização, partindo da noção de espaço, tempo e adquirindo noções mais abstratas (POGGIO, 2002).

Além disso, a preposição "sem" também pode ser utilizada em locuções adverbiais, tais como: "sem dúvida", em que ocorre uma "recategorização sintática e semanticização" (POGGIO, 2002, p.221). Na charge "sem privações" classificada como falta/carência também remete a uma condição do indivíduo, pois pressupõe via negação, que o varredor de rua (contexto pragmático), em comparação com os políticos vive sob privação das necessidades básicas e, ironicamente, a figura do político se dispõe a lhe conceder "lentamente" o que é seu direito, ou seja, condições de vida.

A partir da análise dessa unidade percebe-se que muitas vezes alguns aspectos da língua são negligenciados, pois se apresenta uma proposta generalizante e descontextualizada das formas linguísticas. Neste contexto, caberá ao docente munido de conhecimentos teóricos e práticos vincular o ensino gramatical ao uso e a interação. Para tanto, uma das alternativas residem nos estudos funcionalistas sobre a língua que dedicam a explorar este escopo.

\section{CONSIDERAÇÕES FINAIS}

O avanço das pesquisas realizadas pode ser percebido na preocupação com os aspectos semânticos das preposições, tradicionalmente denominadas "vazias de sentido"; no entanto, os sentidos explicitados no livro didático analisado ainda são restritos, incorrendo em generalizações errôneas. Portanto, os estudos funcionalistas podem contribuir para o ensino gramatical vinculado à interação social, por compreender, por exem- 
plo, que as preposições possuem sentidos prototípicos que se alteram em consonância a diferentes objetivos comunicativos. Contudo, para que tais estudos "ganhem espaço" em sala de aulas fazem-se necessárias capacitações dos docentes, para que o livro didático não seja tomado como bíblia, mas sim como um material a ser expandido.

Nota-se ainda uma preocupação com o discurso institucional de "ensino da língua em uso", a partir de diferentes textos, contudo as tentativas ainda são tímidas, pois o livro didático munido de textos modernos (charges, tiras, dentre outros) "na maior parte das vezes, aparecem como curiosidade ou apenas para garantir ao livro um atestado de engajamento com o mundo que os alunos vivem" (NEVES, 2004, p. 131). Essa atitude faz com que se perca a oportunidade de aproveitar esses textos, destacando as diferentes intenções comunicativas, as relações pragmáticas que operam na seleção gramatical e lexical do enunciado. Ou seja, um rico material acaba sendo renegado ao mero recorte e cole substantivos/preposições presentes nos textos.

Portanto, na presente análise pode-se observar que o discurso de ensinar língua materna em consonância ao domínio dos usos da linguagem já foi incorporado, cabe agora buscar respaldo teórico e metodológico que fundamente essa prática, muitas vezes somente teorizada. Dentre os caminhos possíveis destacam-se os estudos funcionalistas que analisam a língua em situações reais de uso, logo, vinculadas à diferentes atividades discursivas que emanam diferentes formas linguísticas.

\section{REFERÊNCIAS}

ALMEIDA, N. M. Gramática Metódica da língua portuguesa. 45. ed. Saraiva: São Paulo, 2005.

ANTONIO, J. D. Algumas contribuições do funcionalismo e da linguística textual para o ensino de gramática na escola. Revista Acta Sci. Human Soc. Sci., v. 27, n. 1. , p. 1-6, 2005

AZEREDO, J. C. Gramática Houaiss. São Paulo: Publifolha, 2010.

BATORÉO, H. J. Expressão do Espaço no Português Europeu Contributo Psicolinguístico para o Estudo da Linguagem e Cognição. 
Fundação Calouste Gulbenkian - Fundação para a Ciência e a Tecnologia. Ministério da Ciência e Tecnologia. Coimbra, 2000.

BRASIL, Secretaria de Educação Fundamental. Parâmetros Curriculares Nacionais: primeiro e segundo ciclos do ensino fundamental: língua portuguesa. Brasília: MEC/SEF, 1997.

CASTILHO, A. T. de. Gramática do Português Brasileiro. São Paulo: Contexto, 2010, p. 583-610.

. Diacronia das preposições do eixo transversal no português brasileiro. In. NEGRI, L.; FOLTRAN, M. J.; OLIVEIRA, R. P. de (Orgs.). Sentido e significação: em torno da obra de Rodolfo Ilari. São Paulo: Contexto, 2004. p. 11-47.

. Mudança linguística multissistêmica. Coletânea de trabalhos apresentados no XI Simpósio Nacional de Letras e Linguística e I Simpósio Internacional de Letras e Linguística. Uberlândia, 2006. p. 505-518. Disponível em <http://www.filologia.org.br/ileel/artigos/ artigo_510.pdf $>$ acesso em 15 de julho de 2012.

. Proposta funcionalista de mudança linguística. p. 01-32.

Disponível em < http://www.fflch.usp.br/dlcv/lport/pdf/ATCastilho001. pdf $>$. Acesso em 15 de julho 2012.

CUNHA, C.; CINTRA, L. Nova Gramática do Português

Contemporâneo. Rio de Janeiro: Lexikon, 2007.

FURTADO DA CUNHA, M.; OLIVEIRA, A. R.; MARTELOTTA, M. (org.) Línguística funcional: teoria e prática. Rio de Janeiro: DP\&A, 2003.

GONÇALVES, S. C. L.; LIMA-HERNANDES, M. C.; CASSEBGALVÃO, V. C. Introdução à gramaticalização. São Paulo: Parábola, 2007.

HINTZE, A. C. J. Contribuições de pressupostos básicos do funcionalismo para a análise de textos do gênero notícia nos meios 
impresso, televisivo e on line. In: ANTONIO, J.; DESIDERATO, J. (org.) $O$ texto como objeto de ensino, de descrição linguística e de análise textual e discursiva. Maringá: EDUEM, 2009.

HOUAISS. Dicionário da língua portuguesa. Rio de Janeiro: Objetiva, 2009.

KRAVCHENKO, A. Cognitive linguistics, biology of cognition and biosemantics: bridging the gaps. Language Sciences, n. 28, 2006, p. 51-75.

NEVES, M.H. de M. Gramática de usos do português. São Paulo: Editora UNESP, 2000.

A gramática história, teoria e análise, ensino. São Paulo: UNESP, 2002.

. Que gramática estudar na escola? Norma e uso na Língua Portuguesa. São Paulo: Contexto, 2004.

.Texto e gramática. São Paulo: Contexto, 2006.

POGGIO, R. M. G. F. Processos de gramaticalização de preposições do latim ao português: uma abordagem funcionalista. Salvador: EDUFBA, 2002.

SARMENTO, L. L. Português leitura produção gramática. 2. ed. São Paulo: Moderna, 2006.

SAID ALI, M. Gramática Secundária e Gramática Histórica da Língua Portuguêsa. 3. ed. Universidade de Brasília: Brasília, 1964.

SAID ALI, M. Gramática Histórica da língua portuguesa. 8. ed. São Paulo: Melhoramentos, 2001.

SARMENTO, L. L. Português: leitura, produção, gramática. 1. ed. São Paulo: 
Moderna, 2002. Volume 2.

Recebido em: 24/07/17 Aprovado em: 31/07/2017 